\title{
Haloaldehyde Polymers LIII. Optical Resolution of Purely Isotactic Oligomers of Chloral: Optical Activity of the Chloral Oligomers Assuming One-Handed Helical Conformation in Solution
}

\author{
Koichi Ute, Ken-ichi OKa, Yoshio OKamoto,* \\ Koichi Hatada, ${ }^{\dagger} \mathrm{Fu} \mathrm{XI},{ }^{* *}$ and Otto VogL ${ }^{* *}$ \\ Department of Chemistry, Faculty of Engineering Science, \\ Osaka University, Toyonaka, Osaka 560, Japan \\ * Department of Applied Chemistry, Faculty of Engineering, \\ Nagoya University, Nagoya 464, Japan \\ ** Polytechnic University, 333 Jay Street, \\ Brooklyn, NY 11201, U.S.A.
}

(Received June 12, 1991)

\begin{abstract}
The $t$-butoxy-initiated, acetate end-capped, purely-isotactic oligomers of trichloroacetaldehyde (chloral) - from dimer to nonamer- were resolved into the two enantiomers ( $R R R \cdots R$ and $S S S \cdots S$ isomers) by HPLC using a chiral stationary phase. The (-)-isomer eluted faster than the $(+)$-isomer for each oligomer racemate. The $(-)$-isomers were identified as the $R R R \cdots R$ isomers which exist in a right-handed $4_{1}$-helical conformation in solution as well as in the crystalline state. The specific rotation of the oligomer in solution was not significantly dependent on the degree of polymerization, and gave a value, $[\alpha]_{D}=-23.7^{\circ}$ in chloroform for the (-)-pentamer. CD spectra of the optically pure dimer and pentamer were also examined. KEY WORDS Polychloral / Optical Resolution / Specific Rotation / NMR Spectroscopy / Aldehyde Polymerization / Circular Dichroism / Helical Conformation / HPLC /
\end{abstract}

Isotactic oligomers may be defined as a series of stereoisomers which consist entirely of meso diad ( $d d$ or $l l)$ sequences. If the oligomer molecule carries non-identical end groups $(\mathrm{X} \neq \mathrm{Y})$, each isotactic oligomer consists of the two enantiomers, $\mathrm{X}-d d d \cdots d$-Y and $\mathrm{X}-l l l \cdot \cdots l$ $Y$. As the degree of polymerization of the oligomers becomes very large and the end groups are then negligible, both enantiomers can be regarded as pseudoasymmetric and should show very little optical activity due to the individual asymmetric carbon atoms. ${ }^{1,2}$ This was found to be the case for the optically resolved isotactic oligomers of methyl methacrylate $(X=1$-naphthyl, $Y=H){ }^{3}$

\footnotetext{
† To whom correspondence should be addressed.
}

It was recently found that the $t$-butoxyinitiated, acetate end-capped, purely-isotactic oligomers of chloral [1] $(2 \leq n \leq 6)$ had a $4_{1}$-helical structure in solution as well as in the crystalline state. ${ }^{4-6}$

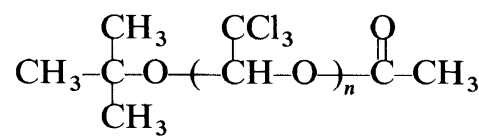

The $R R R \cdots R$ isomers of 1 existed in the right-handed helix approximating the repeat gauche $(-)-\operatorname{skew}(+)(\bar{g} s)$ arrangements from the $t$-butoxy terminal to the acetyl terminal (and the $S S S \cdots S$ isomers adopted the left-handed helix). The helix-sense preference 
originates from the conformational energy difference between the right- $(\bar{g} s)_{n}$ and lefthanded $(\bar{s} g)_{n}$ states, which was estimated as $2.7 \mathrm{kcal} \mathrm{mol}^{-1}$ by molecular mechanics calculation for the $(R, R, R, R, R)$-pentamer. ${ }^{6,7}$ Consequently, the $R R R \cdots R$ and $S S S \cdots S$ isomers are expected to show optical activity based not only on asymmetric carbons but also on conformational asymmetry.

Some isotactic polymers such as polychloral ${ }^{8-13}$ and poly(triphenylmethyl methacrylate $)^{14}$ are known to show high optical rotation when the polymers are prepared by asymmetric polymerization; the polymerization of chloral with chiral alkoxide such as the lithium salt of $(R)-(-)-2$-octanol ${ }^{12}$ or steroid alkaloids ${ }^{13}$ leads to the formation of polychloral films with specific rotation exceeding $1000^{\circ}$. The optical activity was ascribed to the polymeric helices with one-handed screw sense which were predominantly or preferentially formed during the polymerization. Optically active $\mathbf{1}$ is considered to be a good model of such polymers. Moreover, the optical activity of the chloral oligomers in solution is of particular interest because polychloral is insoluble in any organic solvent. ${ }^{15}$

\section{EXPERIMENTAL}

The $t$-butoxy-initiated, acetate end-capped oligomer of chloral 1 was prepared as reported previously. ${ }^{16,17}$<smiles>CC(C)(C)[14CH2][14C](Cl)(Cl)Cl</smiles>

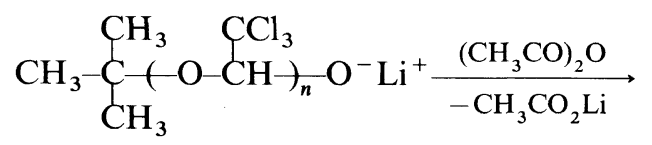<smiles>CC(=O)OC(OC(C)(C)C)C(Cl)(Cl)Cl</smiles>

The polymerization of chloral is highly isotactic-specific, and the oligomers above the dimer level $(n \geq 3)$ consisted exclusively of purely-isotactic oligomers. The unimer and dimer fractions were separated from the oligomer mixture by distillation. The residue (bp $>170^{\circ} \mathrm{C} / 0.075$ Torr) consisted of the soluble oligomers from trimer to nonamer. Each oligomer was isolated by GPC using a $2 \mathrm{~cm}$ (i.d.) $\times 50 \mathrm{~cm}$ column packed with polystyrene gel (maximum porosity $=3000$ ) using chloroform as eluent $\left(2.4 \mathrm{ml} \mathrm{min}^{-1}\right)$. The oligomers isolated were purified by recrystallization from methanol.

The optical resolution of the oligomers was performed on a JASCO TRIROTAR-II chromatograph equipped with a Shodex RI SE-61 refractive index detector and a JASCO DIP$181 \mathrm{C}$ polarimetric detector $(\mathrm{Hg}$ lamp, without filter). Cellulose tris(3,5-dimethylphenylcarbamate) coated on macroporous silica gel (particle size $7 \mu \mathrm{m})^{3,18,19}$ was used as a stationary phase $(0.46 \mathrm{~cm}$ (i.d. $) \times 25 \mathrm{~cm}$ column), and hexane was employed as a mobile phase $\left(0.5 \mathrm{ml} \mathrm{min}^{-1}\right)$.

The optical rotations were measured at $25^{\circ} \mathrm{C}$ on a JASCO DIP181 digital polarimeter using a $50 \mathrm{~mm}$ cell. CD spectra were recorded on a JASCO-J40 CD apparatus using a $0.1 \mathrm{~mm}$ cell. ${ }^{13} \mathrm{C}$ NMR spectra were measured on a JEOL JNM-GX500 spectrometer.

\section{RESULTS AND DISCUSSION}

Optical resolution of the isotactic chloral oligomers 1 from dimer to nonamer $(2 m \cdots$ 9 mimmmmmmm) was performed on the HPLC using a chiral stationary phase. Figure 1 shows chromatograms for the pentamer $(5 \mathrm{mmmm})$ and octamer $(8 \mathrm{mmmmmmm})$ fractions. For every fraction, the $(-)$-isomer eluted faster than the $(+)$-isomer. Table I summarizes the capacity factor, $k_{-}^{\prime}=\left(t_{-}-t_{0}\right) / t_{0}$, the separation factor, $\alpha=k_{+}^{\prime} / k_{-}^{\prime}$, and the resolution factor, $R_{\mathrm{s}}=2\left(t_{+}-t_{-}\right) /\left(W_{-}+W_{+}\right)$, for the chromatographic resolution of the oligomers, where $t_{0}, t_{-}, t_{+}, W_{-}$and $W_{+}$denote the dead time of the column, the retention times of the 
$(-)$ - and (+)-isomers, and the band widths for the (-)- and (+)-isomers, respectively ( $c f$. Figure $1 \mathrm{~b}$ ). ${ }^{20}$ As can be seen from the $R_{\mathrm{s}}$ values in Table $\mathrm{I}$, the enantiomers of $2 \mathrm{~m}, 3 \mathrm{~mm}$, $5 \mathrm{mmmm}$ and $8 \mathrm{mmmmmmm}$ separated completely $\left(R_{\mathrm{s}}>1.0\right)$ whereas those of the other oligomers, particularly $4 \mathrm{mmm}$ and $7 \mathrm{mmmm}$ $\mathrm{mm}$, did partially. It is interesting to note that the oligomers with a degree of polymerization $n=2+3 i(i=0,1,2)$ were resolved well while
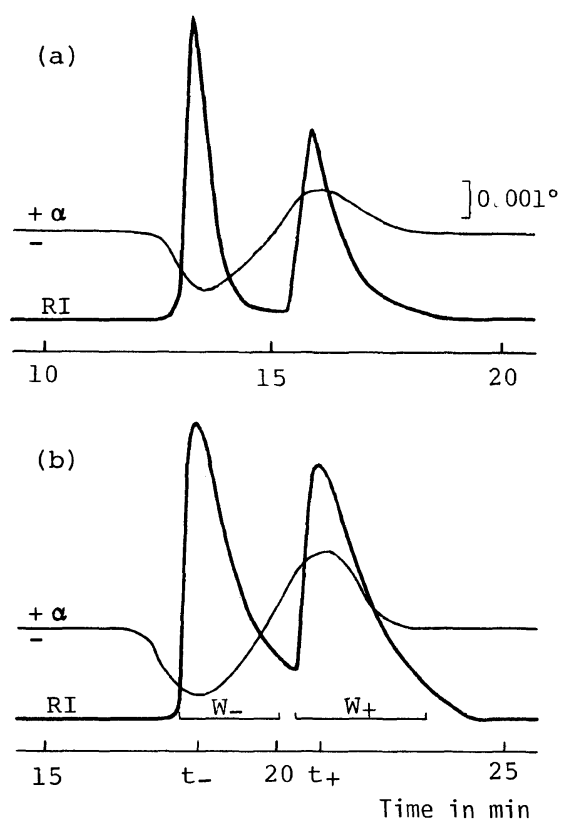

Figure 1. HPLC traces of the isotactic pentamer $(5 \mathrm{mmmm})$ (a) and octamer (8mmmmmmm) (b) of chloral. those of $n=4+3 i \quad(i=0,1)$ were not. The periodical behavior of the chromatographic resolution may be related to the helical structure of the oligomers; the chiral discrimination on the stationary phase is considered to be based not only on the absolute configuration and helical sense of the oligomers but also on the relative arrangement of the $t$-butyl and acetyl terminals.

Optically pure enantiomers of $2 m$ and $5 \mathrm{mmmm}$ were isolated by HPLC and were purified by recrystallization from methanol. $\mathrm{X}$-ray crystallographic analysis of $(-)-5 \mathrm{~mm}$ $m m$ will be described elsewhere ${ }^{6,21}$ together with that of racemic $5 \mathrm{mmmm}$. Specific rotations, $[\alpha]_{\mathrm{D}}$ and $[\alpha]_{365}$, of the pure enan-

Table I. Optical resolution of chloral oligomers by HPLC

\begin{tabular}{lccc}
\hline & $k_{-}^{\prime}$ & $\alpha$ & $R_{\mathrm{s}}$ \\
\hline $2 \mathrm{~m}$ & 0.95 & 1.61 & 3.89 \\
$3 \mathrm{~mm}$ & 0.63 & 1.24 & 1.38 \\
$4 \mathrm{mmm}$ & 0.97 & 1.12 & 0.74 \\
$5 \mathrm{mmmm}$ & 1.22 & 1.34 & 1.67 \\
$6 \mathrm{mmmmm}$ & 1.50 & 1.17 & 0.73 \\
$7 \mathrm{mmmmmm}$ & 1.87 & 1.06 & 0.33 \\
$8 \mathrm{mmmmmmm}$ & 2.07 & 1.21 & 1.04 \\
$9 \mathrm{mmmmmmmm}$ & 2.48 & 1.15 & 0.89
\end{tabular}

a Stationary phase: cellulose tris(3,5-dimethylphenylcarbamate); mobile phase: hexane, $0.5 \mathrm{ml} \mathrm{min}^{-1} ; k_{-}^{\prime}$, capacity factor for the $(-)$-isomer; $\alpha$, separation factor, $\alpha=k_{+}^{\prime} / k_{-}^{\prime} ; R_{\mathrm{s}}$, resolution factor.

Table II. Specific rotation of the isotactic dimer $(2 \mathrm{~m})$ and pentamer $(5 \mathrm{mmmm})$ of chloral measured in various solvents ${ }^{\mathrm{a}}$

\begin{tabular}{|c|c|c|c|c|c|c|}
\hline & \multirow{2}{*}{$\frac{[\alpha]_{\mathrm{D}}^{25}}{\mathrm{CHCl}_{3}}$} & \multicolumn{4}{|c|}{$[\alpha]_{365}^{25}$} & \multirow{2}{*}{$\frac{c}{\mathrm{~g} \mathrm{dl}^{-1}}$} \\
\hline & & $\mathrm{CHCl}_{3}$ & $\mathrm{C}_{6} \mathrm{H}_{14}$ & $\mathrm{CH}_{3} \mathrm{OH}$ & $\mathrm{C}_{6} \mathrm{H}_{6}$ & \\
\hline $\begin{array}{l}(+)-2 m \\
(-)-2 m\end{array}$ & $\begin{array}{l}+22.9 \\
-21.7\end{array}$ & $\begin{array}{l}+57.4 \\
-57.0\end{array}$ & $\begin{array}{l}+65.4 \\
-65.5\end{array}$ & $\begin{array}{l}+62.5 \\
-62.6\end{array}$ & $\begin{array}{l}+1.2 \\
-1.2\end{array}$ & $\begin{array}{l}1.589 \\
1.687\end{array}$ \\
\hline $\begin{array}{l}(+)-5 m m m m \\
(-)-5 m m m m^{\mathrm{b}}\end{array}$ & $\begin{array}{l}+22.6 \\
-23.7\end{array}$ & $\begin{array}{l}+62.9 \\
-63.1\end{array}$ & $\begin{array}{l}+60.0 \\
-63.3\end{array}$ & $\begin{array}{l}+60.7 \\
-59.6\end{array}$ & $\begin{array}{l}-9.3 \\
+9.1\end{array}$ & $\begin{array}{l}0.887 \\
0.792\end{array}$ \\
\hline
\end{tabular}

a Cell length $=5.0 \mathrm{~cm}$. " $c$ " denotes the concentration of the chloroform solution.

b Absolute configuration was determined as $(R, R, R, R, R)$ by X-ray single crystal analysis; $(R, R, R, R, R)-(-)-5 \mathrm{mmmm}$ adopted right-handed $4_{1}$-helical conformation. ${ }^{6,21}$ 


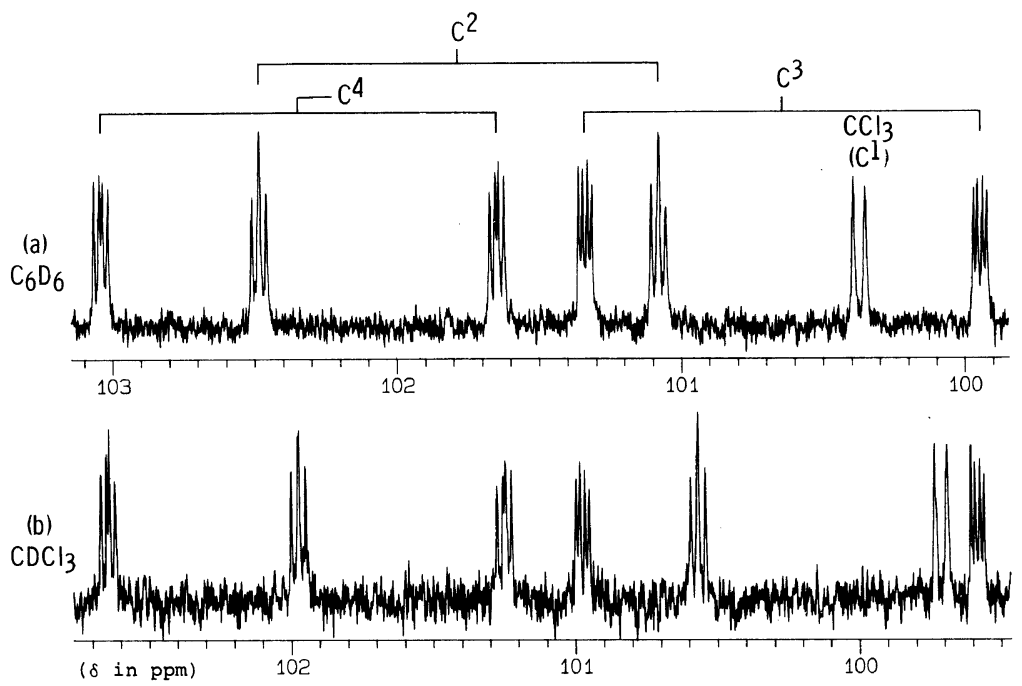

Figure 2. ${ }^{1} \mathrm{H}$-Coupled ${ }^{13} \mathrm{C}$ NMR spectra of $5 \mathrm{mmmm}$ (the acetal carbons region) measured in benzene- $d_{6}$ (a) and in chloroform- $d$ (b) at $35^{\circ} \mathrm{C}(125 \mathrm{MHz})$. The numbering system for the acetal carbons is as follows:<smiles>CC(=O)OC(OC(Cl)(C(Cl)(Cl)Cl)C(Cl)(Cl)Cl)C(OC(C(C)(C)C)C(Cl)(Cl)Cl)OC(C(Cl)(Cl)Cl)C(Cl)(Cl)Cl</smiles>

tiomers of $2 \mathrm{~m}$ and $5 \mathrm{mmmm}$ were measured in chloroform, hexane, methanol and benzene (Table II). The $[\alpha]_{365}$ values measured in benzene were very different from those measured in the other solvents. However, the conformation of $5 \mathrm{mmmm}$ in chloroform- $d$ and in benzene- $d_{6}$ was essentially identical according to the ${ }^{3} J_{\mathrm{COCH}}$ coupling constants ${ }^{22}$ observed in ${ }^{13} \mathrm{C}$ NMR spectra (Figure 2). The peculiar $[\alpha]_{365}$ values of $2 \mathrm{~m}$ and $5 \mathrm{mmmm}$ in benzene is considered to be induced by the benzene molecules interacting with trichloromethyl groups of the chloral oligomers. The specific interaction between polychloral and aromatic compounds was suggested by NMR analysis ${ }^{23}$ and by liquid chromatography. ${ }^{24}$ The $[\alpha]_{365}$ values of optically pure $2 \mathrm{~m}$ and $5 \mathrm{mmmm}$ in chloroform were essentially constant in the temperature range from -60 to $+60^{\circ} \mathrm{C}$.

The $[\alpha]$ values for $2 m$ and $5 \mathrm{mmmm}$ were similar to each other. Moreover, the values seemed to be independent of the degree of polymerization, $n$, below the nonamer level, since the relative intensities of the elution curves detected by polarimetric and RI detectors were nearly equal for all the oligomers (cf. Figure 1). The results suggest that the $[\alpha]$ values of polychloral with one-handed helical conformation in solution may not be as large as those reported for the polychloral film samples $\left(>1000^{\circ}\right)^{8-13}$ prepared by helix-sense selective polymerization. It should be remembered that measurements of optical activity in dilute solution consists of the measurements on individual molecules but that of the solid state of molecule aggregates. Such differences have been shown to exist not infrequently. ${ }^{25-27}$

Figure 3 shows CD spectra of $(-)-2 m$ and $(-)-5 \mathrm{mmmm}$. The $(+)$-isomers exhibited the CD patterns complementary to those of the corresponding (-)-isomers. For wave lengths shorter than $225 \mathrm{~nm}$, the $C D$ patterns of (-) $-2 m$ and (-) $-5 m m m m$ were similar to each other except that the molar elipticity $[\theta]$ of $(-)-2 m$ was about $5 / 2$ times as large as that 


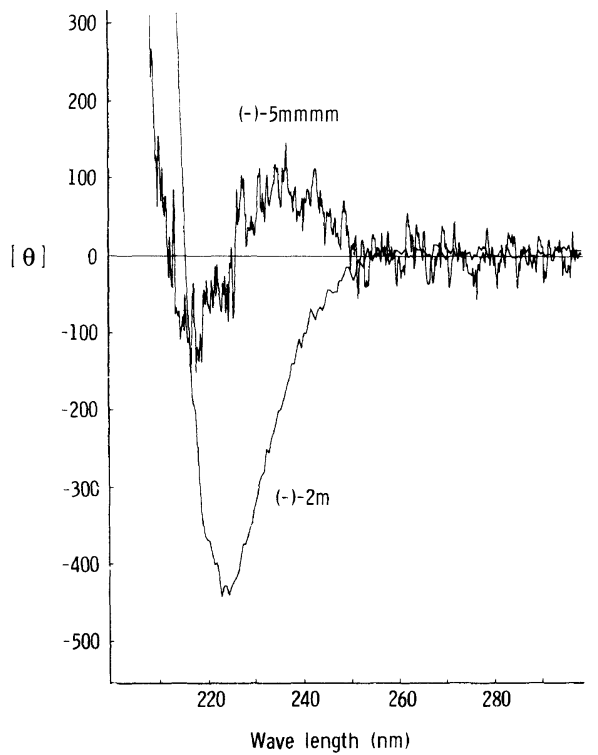

Figure 3. CD spectra of the (-)-dimer $((-)-2 m)$ and $(-)$-pentamer $((-)-5 \mathrm{mmmm})$ of chloral (hexane, $(-)-2 \mathrm{~m}$ : $0.162 \mathrm{moll}^{-1}, \lambda_{\max }=194 \mathrm{~nm}\left(\varepsilon=1.1 \times 10^{3}\right) ;(-)-5 \mathrm{mmmm}$ : $\left.0.0302 \mathrm{moll}^{-1}, \lambda_{\max }=193 \mathrm{~nm}\left(\varepsilon=3.0 \times 10^{3}\right)\right)$.

of (-)-5mmmm. This suggests that the elipticities should be due to the carbonyl moiety of the terminal acetyl group $\left(n-\pi^{*}\right)$ and that the acetal carbon atoms adjacent to the acetyl groups of (-)-2m and (-)-5mmmm have the same absolute configuration. From X-ray crystallographic analysis, the absolute configuration of $(-)-5 \mathrm{mmmm}$ was determined as $(R, R, R, R, R) ;^{6,21} \quad(R, R, R, R, R)-(-)-5 m m m m$ was suggested to exist predominantly in a right-handed $4_{1}$-helical conformation in solution at room temperature as wall as in the crystalline state. For the wave lengths from $225 \mathrm{~nm}$ to $250 \mathrm{~nm}$, the molar elipticity of (-)-5mmmm was positive whereas that of (-)-2m was negative. The positive elipticity of (-) $-5 \mathrm{mmmm}$ around the $225-250 \mathrm{~nm}$ region can be attributed to the right-handed helical structure, if we consider that the acetal backbone of $(-)-2 m$ is too short to form a full turn of a $4_{1}$-helix.

Further studies on the optical activity of chloral oligomers are now under way using the isotactic chloral oligomers carrying an identical end-group at both ends. Those oligomers are the $(R R \cdots R S \cdots S S)$-( \pm$)$-isomers having a plane of symmetry in the molecule. Recently, it was suggested that the isotactic chloral oligomers having a methyl group at both ends over the pentamer level may be optically resolved at room temperature based entirely on conformational asymmetry. ${ }^{28}$

Acknowledgments. This work was supported by the Grant-in-Aid for Scientific Research (Nos. 03453118, 03750665) from the Ministry of Education, Science, and Culture of Japan, and by the Herman F. Mark Chair of the Polytechnic University.

\section{REFERENCES AND NOTES}

1. H. L. Frisch, C. Schuerch, and M. Szwarc, J. Polym. Sci., 11, 559 (1953).

2. C. L. Arcus, J. Chem. Soc., 2801 (1955); ibid., 1189 (1957).

3. Y. Okamoto, T. Nakano, and K. Hatada, Polym. J., 21, 199 (1989).

4. O. Vogl, F. Xi, F. Vass, K. Ute, T. Nishimura, and K. Hatada, Macromolecules, 22, 4658 (1989).

5. K. Ute, T. Nishimura, K. Hatada, F. Xi, F. Vass, and O. Vogl, Makromol. Chem., 191, 557 (1990).

6. K. Ute, K. Oka, Y. Okamoto, K. Hatada, and O. Vog1, Polym. Prepr. Jpn., 39, 1739 (1990).

7. K. Ute, K. Oka, and K. Hatada, to be submitted to Polym. J.

8. L. S. Corley and O. Vogl, Polym. Bull., 3, 211 (1980).

9. O. Vogl, The Chemist (American Institute of Chemists), 16, 62 (1985).

10. L. S. Corley, G. D. Jaycox, and O. Vogl, J. Macromol. Sci.-Chem., A25, 519 (1988).

11. W. J. Harris and O. Vogl, J. Macromol. Sci.-Chem., A26, 1067 (1989); ibid., A26, 1083 (1989).

12. G. D. Jaycox and O. Vogl, Polym. Commun., 30, 354 (1989).

13. G. D. Jaycox and O. Vogl, Makromol. Chem., Rapid Commun., 11, 61 (1990).

14. Y. Okamoto, K. Suzuki, K. Ohta, K. Hatada, and H. Yuki, J. Am. Chem. Soc., 101, 4763 (1979).

15. P. Kubisa, L. S. Corley, T. Kondo, M. Jacovic, and O. Vogl, Polym. Eng. Sci., 21, 829 (1981).

16. J. Zhang, G. D. Jaycox, and O. Vogl, Polymer, 29, 707 (1988).

17. K. Hatada, K. Ute, T. Nakano, F. Vass, and O. Vogl, Makromol. Chem., 190, 2217 (1989).

18. Y. Okamoto, M. Kawashima, and K. Hatada, J. 
Chromatogr., 363, 173 (1986).

19. Y. Okamoto, E. Yashima, T. Nakano, and K. Hatada, Chem. Lett., 759 (1987).

20. For the definition of $k^{\prime}, \alpha$ and $R_{\mathrm{s}}$ values, see for example: L. R. Snyder and J. J. Kirkland in "Introduction to Modern Liquid Chromatography," John Wiley \& Sons, New York, N.Y., 1974, Chapter 2.

21. K. Ute, K. Oka, Y. Matsuura, K. Hatada, and O. Vogl, to be submitted to Polym. $J$.

22. The long-range coupling constants ${ }^{3} J_{\mathrm{COCH}}$ are known to depend on the dihedral angle $\phi$ in the ${ }^{13} \mathrm{C}-\mathrm{O}-\mathrm{C}-{ }^{1} \mathrm{H}$ arrays as follows [R. Yamada and I. Ando, Polym. Prepr. Jpn., 32, 835 (1983)]: ${ }^{3} J_{\mathrm{COCH}}=2.21 \cos 2 \phi-$
$1.03 \cos \phi+3.64$

23. O. Vogl and K. Hatada, J. Polym. Sci., Polym. Lett., 13, 603 (1975).

24. K. Hatada, T. Kitayama, S. Shimizu, H. Yuki, W. Harris, and O. Vogl, J. Chromatogr., 248, 63 (1982).

25. J. Bartus, L. S. Corley, G. D. Jaycox, and O. Vogl, Polym. Prepr. Jpn., 36, E23 (1987).

26. P. Pino, J. Bartus, and O. Vogl, Polym. Prepr., ACS Div. Polym. Chem., A9(1), 254 (1988).

27. O. Vogl, J. Bartus, and J. R. Murdoch, Monatsh. Chem., 121, 311 (1990).

28. K. Ute, K. Hirose, H. Kashimoto, K. Hatada, and O. Vogl, J. Am. Chem. Soc., 113, 6305 (1991). 